\title{
O reconhecimento da independência de Angola e a formação da comunidade do Atlântico Sul
}

\author{
Rafaelle Leite de Sousa
}

\begin{abstract}
LIMA, S. E. M.; VILLAFAÑE, L. C. (Org). Quarenta anos das relações Brasil-Angola: documentos e depoimentos. Brasília: FUNAG, 2015.
\end{abstract}

Quarenta Anos das relações Brasil-Angola, obra organizada pela Fundação Alexandre de Gusmão, faz parte de uma política africanista que ganhou força a partir do governo Lula. Trata-se de uma volta aos princípios do que já fazia parte da história diplomática brasileira, mas agora com novos contextos: acrescentou-se ao conteúdo do antirracismo o teor da política de inclusãoe a valorização de uma cultura negra, especialmente a feminina. É nesse campo que se insere a extensa produção acadêmica que busca aproximar Brasil e África, bem como a criação e reprodução de instrumentos, com o propósito de fortalecer uma identidade do Atlântico Sul.

A escravidão é uma marca perversa no histórico de relações entre Brasil e África e vem sendo contornada pelas ações que buscam reverter o mal-estar resultante de séculos de exploração. É com esse propósito que a Fundação Alexandre de Gusmão lança a obra ora apresentada, tendo como fato de grande expressividade da diplomacia brasileira o reconhecimento da independência angolana, em 11 de novembro de 1975. Trata-se de uma tentativa de guardar a memória de um histórico de relações que, para

\section{$\overline{\text { Rafaelle Leite de Sousa }}$}

Graduada em Ciências Sociais pela Universidade Federal do Ceará e mestranda em Políticas Públicas e Sociedade pela Universidade Estadual do Ceará.

rafaelleleite84@hotmail.com 
Rafaelle Leite de Sousa

o Brasil, tem uma simbologia bastante representativa. Bem destacado no livro, o fato tornou-se controverso, tendo em vista que, naquela data, o grupo político no poder enfrentava o que os militares hoje costumam denominar de "guerra" ao comunismo.

No primeiro capítulo do livro, o autor Sérgio Eduardo Moreira, embaixador e presidente da FUNAG e dono de vasta experiência política e social no Oriente Médio, aborda a importância do reconhecimento brasileiro da independência angolana. Nele, é relevante a afirmação de que o projeto de nação angolana se concebeu antes da democracia, uma situação recorrente à formação de Estados nacionais no século XX. Segundo o autor, as consequências das duas guerras mundiais foram decisivas para uma reconstrução dos valores sociais e humanos, de modo que a colonização não seria mais aceita. Por outro lado, o autor aponta para uma possível ambiguidade, haja vista o que foi apresentado no Tratado de Consulta e Amizade. Destinado a preservar os laços amigáveis entre Brasil e Portugal, o tratado foi assinado em 1953, com o propósito de prosseguir com a formação de uma possível Comunidade Luso-Brasileira, garantir direitos iguais aos cidadãos de ambas nacionalidades e buscar solidariedade na resolução de conflitos internacionais.

Assim, o Brasil entra no processo de descolonização africana como um mediador, voltando-se para a ideia de construção de uma comunidade lusófona. Na história da diplomacia brasileira, a posição anticolonial e antirracista só foi abertamente defendida com a Política Externa Independente, predominante nos governos João Goulart e Jânio Quadros, caracterizando-se pela defesa da independência econômica e ideológica brasileira. Nessa perspectiva, a posição do país, nos discursos da ONU, foi de encontro ao "americanismo" vigente e avançou lentamente na defesa do princípio da autodeterminação dos povos.

A política externa brasileira tem como pressuposto a ideia de resolução pacífica de conflitos, sendo essa ideia fortemente atribuída ao contexto geral do Estado brasileiro. Diante da postura adotada por dirigentes políticos na época das disputas anticoloniais na África, especificamente nas colônias portuguesas, as autoridades brasileiras não tiveram êxito em formalizar, 
O RECONHECIMENTO DA INDEPENDÊNCIA DE ANGOLA E A FORMAÇÃO DA COMUNIDADE DO ATLÂNTICO SUL

perante a metrópole, a cobrança pela liberdade das antigas colônias. Destaca-se o caso especial de Angola e o discurso de Afonso Arinos, na Assembleia Geral da ONU de 1961, que revela a disposição do Brasil em defender a autodeterminação dos povos colonizados. Essa disposição representava a luta contra o subdesenvolvimento e a consolidação da justiça entre os Estados nacionais, tendo obtido continuidade com o chanceler San Tiago Dantas, sucessor de Arinos.

O autor volta a dissertar sobre as ambiguidades do período da ditadura civil-militar brasileira, ao informar que aquele governo nacional reconheceu o governo de esquerda do Movimento para a Libertação de Angola (MPLA). Além disso, recupera a história brasileira e a sua luta contra o processo colonial, já que também esteve sob julgo português. Considera "exitosa" a política pós-colonial no Brasil, quando houve a transferência da corte portuguesa para o Rio de Janeiro, o que possibilitou uma estabilidade e consolidação da "identidade nacional".

Seguindo o propósito de descrever quão valiosas são as relações entre Brasil e Angola, o autor relata o esforço da diplomacia brasileira na defesa do anticolonialismo, apesar da existência do Tratado de Consulta e Amizade. Para tomar a decisão de apoiar o fim do regime colonial angolano, o Brasil teve queser cauteloso para não pôr em risco uma relação que estava legitimada por acordos históricos. Assim, os arranjos diplomáticos tiveram de colocar em destaque a necessidade de ampliar a referida comunidade e, acima de tudo, os valores democráticos e humanitários.

Sérgio Eduardo Moreira também colocou em debate os dilemas dessa época, inclusive a luta pelo desarmamento, o grande drama da era bipolar. Certamente a decisão brasileira foi bastante complexa, pois o autor deixa claro que havia um alinhamento automático do Brasil com os Estados Unidos e, diante das circunstâncias, apoiar um governo comunista significava atuar por meio de uma diplomacia firme e bem orientada.

Em Angola, a situação era profundamente complicada, pois três movimentos estavam em disputa, tendo prevalecido o carisma e a liderança de Agostinho Neto, do MPLA. O reconhecimento do seu governo por parte do presidente brasileiro Ernesto Geisel se 
Rafaelle Leite de Sousa

deu com base em uma orientação inaugurada por ele eadotada pelo Itamaraty, denominada de "Pragmatismo Responsável". A posição representou uma ruptura com Portugal, expressa em uma circular telegráfica na qual o Brasil defende a manutenção dos laços culturais, mas atenta para a autodeterminação dos povos.

A obra prossegue, em seu segundo capítulo, a partir da análisee relato de Nelson Manuel Cosme, embaixador angolano no Brasil desde 2011, sobre a importância do relacionamento Brasil-Angola. A superação angolana das condições de colônia inicia um processo que, na visão do autor, compactua novas alianças com outros países, que seguiram o exemplo do Brasil e aceitaram o novo país como membro da comunidade internacional.

No mesmo sentido do capítulo anterior, esta parte do livro aborda a relevância do pioneirismo brasileiro em reconhecer a independência de Angola, resultando em uma continuidade de laços diplomáticos. O autor elogia a realização de um seminário comemorativo dos 40 anos de relações entre os dois países e também destaca a posição do Governo Geisel e o trabalho desenvolvido por Olvídio de Melo, embaixador brasileiro presente em Angola, durante todo o ano de 1975, e responsável pelas negociações diplomáticas que formalizaram o reconhecimento da independência angolana.

Ressalta-se, nesse capítulo, a descrição de momentos de incertezas vivenciados desde a independência angolana. Até os anos 2000, período mais significativo, o autor revê o que aconteceu em décadas passadas, demonstrando que a fase do neoliberalismo foi a mais perene. Na mesma perspectiva, há o risco desse momento se repetir, sendo previstos retrocessos na chamada Política de Cooperação Sul-Sul, destinada a buscar e preservar relações com as nações em desenvolvimento, devido à crise política brasileira, iniciada com o processo de impedimento da presidente eleita Dilma Roussef e que ameaça os projetos iniciados na década de 2000. Destaca-se que grande parte desses projetos está em fase de implantação e tende a ser reduzida ou encerrada, como é o caso da implementação de algumas embaixadas na África e da expansão de universidades de integração internacional. Contudo, o autor enfatiza um futuro positivo em relação aos projetos de 
O RECONHECIMENTO DA INDEPENDÊNCIA DE ANGOLA E A FORMAÇÃO DA COMUNIDADE DO ATLÂNTICO SUL

cooperação, nos quais estão ancoradas todas as propostas de estreitamento de laços com países africanos.

No âmbito da Cooperação Sul-Sul, também residem todas as propostas de aproximação com os países africanos. O autor defende esse modelo, acreditando ser o caminho para o desenvolvimento mútuo das nações envolvidas. Na sua percepção, as relações Brasil-Angola trazem uma série de benefícios, dentre eles o apoio à aspiração brasileira de pertencer ao Conselho de Segurança da ONU e o intercâmbio de pesquisadores universitários.

Ao produzir uma análise de documentos, Vilafañe verifica que a postura brasileira estava em desacordo com a tendência anticolonial, posicionando-se ao lado do regime racista em vigor na África do Sul e que, obviamente, acatava o colonialismo. Essa conjuntura trouxe um desconforto diplomático ao Brasil, que representava um grande apoio a Portugal. Os documentos apontam também que havia a preocupação em evitar conflitos, tanto que o Brasil apostava no pacifismo e nas negociações conjuntas, para que não houvesse rompimento diplomático. Uma das propostas era a formação da Comunidade Luso-AfroBrasileira, que representaria uma incorporação ao que propõe o Tratado da Amizade de 1953 e com o que se intensificou a pressão para a consolidação da autodeterminação dos povos.

Pelo que aponta o livro, a tentativa de uma postura conciliadora do Brasil perdurou até 1974. Foi na abertura da XXIX Sessão Ordinária da Organização das Nações Unidas que o discurso diplomático brasileiro foi mais incisivo em favor da autodeterminação, conferindo apoio incondicional à independência das colônias portuguesas. A partir de então, as ações foram mais efetivas, inclusive com envio de pessoal para as negociações, de modo a reconhecer o movimento sociopolítico ao qual seria entregue o governo. Era preciso buscar diálogo com aquele que supostamente estaria mais preparado, assim, o MPLA foi reconhecido. Embora a ele houvesse sido conferido o poder de governança, é preciso ressaltar que a guerra, naquele momento, estava apenas começando. 